\title{
05
}

\section{Эмиссионная активность при ударном разрушении керамик $A_{2} B_{6}$}

\author{
(C) И.П Щербаков ${ }^{1}$, А.А. Дунаев ${ }^{2}$, А.Е. Чмель ${ }^{1, \uparrow}$ \\ ${ }^{1}$ Физико-технический институт им. А.Ф. Иоффе РАН, Санкт-Петербург, \\ Россия \\ ${ }^{2}$ Государственный оптический институт им. С.И. Вавилова, \\ Санкт-Петербург, Россия \\ 『E-mail: chmel@mail.ioffe.ru
}

Поступило в Редакцию 14 июля 2017 г.

В окончательной редакции 27 февраля 2018 г.

Представлены результаты исследования генерации электромагнитной эмиссии при ударном нагружении керамик $\mathrm{ZnS}$ и $\mathrm{ZnSe}$, полученных по различным технологиям. Выбор способа механического воздействия связан с типичными приложениями этих керамик. Показаны раздельные вклады в эмиссионную активность от движения дислокаций и развития микротрещин, зависящих от размеров кристаллитов в керамике. Проведено сопоставление электромагнитной эмиссии с параллельными временнб́ми рядами импульсов механолюминесценции и акустической эмиссии. Эмиссионная активность во всех трех случаях регистрировалась с временны́м разрешением $10 \mathrm{~ns}$.

DOI: $10.21883 /$ PJTF.2018.15.46441.16971

Электромагнитная эмиссия (ЭМЭ) из деформируемых ионных кристаллов [1,2] и ковалентно-ионного кристалла ZnSe [3] была экспериментально обнаружена в 80-х годах прошлого века. Впоследствии был предложен ряд моделей явления, в основе которых лежали поляризационные эффекты при движении дислокаций и их взаимодействие со „стопорами“ [3-6]. Эффект ЭМЭ также хорошо известен в сжатых горных породах, где он связывался с накоплением микротрещин [7,8]. В то же время, насколько нам известно, ЭМЭ никогда не наблюдалась в высокопластичных поликристаллах, в частности в полупроводниковых соединениях $\mathrm{A}_{2} \mathrm{~B}_{6}$. В настоящей работе представлены результаты исследования ЭМЭ, возникающей при ударном повреждении керамик $\mathrm{ZnS}$ и $\mathrm{ZnSe}$. Выбор типа механического воздействия на образцы связан с тем, что кроме расширения понимания природы пластической 
деформации в твердых телах актуальность проблемы обусловлена широким использованием указанных пластичных керамик в оптических устройствах ИК-диапазона, эксплуатируемых вне помещений, где они подвергаются ударам твердых пылевых частиц и атмосферных осадков, повреждающих оптическую поверхность изделий $[9,10]$, в особенности приборов, установленных на мобильных носителях.

При исследовании динамического нагружения поликристаллических материалов важную роль играет определение момента вязкоупругого перехода [11], а в случае высокопластичных керамик - перехода от необратимой деформации к разрушению. Поэтому в целях надежной интерпретации результатов параллельно с ЭМЭ регистрировались механолюминесценция (МЛ) и акустическая эмиссия (АЭ) из повреждаемых образцов; эти методы имеют различную чувствительность к пластической деформации и генерации разрывов сплошности (микротрещин) в твердых телах.

Для определения зависимости эффекта ЭМЭ в керамиках $\mathrm{A}_{2} \mathrm{~B}_{6}$ от их химического состава, механических свойств и структурных особенностей образцы изготавливались по различными технологиям: использованы методы горячего прессования (hot pressing, HP), физического парового осаждения (physical vapor deposition, PVD) и химического парового осаждения (chemical vapor deposition, CVD). В зависимости от метода получения средний размер зерен в образцах составлял от $\sim 1$ до $\sim 10^{3} \mu \mathrm{m}$ (см. таблицу). Некоторые образцы подвергались дополнительной обработке методом горячего изостатического прессования (hot isostatic pressing, HIP), которая посредством рекристаллизации почти устраняет межкристаллитные границы, при этом формируются тонкие равновесные слои между крупными зернами [12].

Повреждение образцов, изготовленных в виде полированных дисков диаметром 20-30 mm и толщиной 1-2 mm, производилось ударом груза, падающего на заостренный стальной боек, поставленный на поверхность образца. ЭМЭ регистрировалась с помощью диполя Герца. Свечение МЛ собиралось кварцевой линзой и направлялось на фотоумножитель ФЭУ-136. Поскольку соединения $\mathrm{A}_{2} \mathrm{~B}_{6}$ обладают пьезоэлектрическими свойствами, детектором АЭ служила пластина из высокочувствительной пьезокерамики $\mathrm{Pb}\left(\mathrm{Zr}_{x} \mathrm{Ti}_{1-x}\right) \mathrm{O}_{3}$, пьезоэлектрический коэффициент которой более чем на два порядка величины превышает таковой для исследованных керамик. Сигналы ЭМЭ, МЛ и АЭ поступали на вход аналогово-цифрового преобразователя АСК-3106

Письма в ЖТФ, 2018, том 44, вып. 15 
Приблизительный размер зерен в керамиках $\mathrm{ZnS}$ и $\mathrm{ZnSe}$, полученных различными методами

\begin{tabular}{c|c|c}
\hline Материал & Метод получения & Размер зерен, $\mu \mathrm{m}$ \\
\hline $\mathrm{ZnS}$ & $\mathrm{HP}$ & $\sim 1$ \\
$\mathrm{ZnS}$ & $\mathrm{CVD}$ & $10-20$ \\
$\mathrm{ZnS}$ & $\mathrm{CVD}+\mathrm{HIP}$ & $100-250^{*}$ \\
$\mathrm{ZnSe}$ & $\mathrm{PVD}+\mathrm{HIP}$ & $1000-1500^{*}$
\end{tabular}

* Границы между кристаллитами выражены слабо.

и в цифровой форме сохранялись в компьютере. Продолжительность сбора сигналов всех типов составляла $1 \mathrm{~ms}$. Временно́е разрешение $10 \mathrm{~ns}$.

На рис. 1 показаны временны́е развертки абсолютной амплитуды ЭМЭ из керамик $\mathrm{ZnS}$, полученных различными методами. Можно видеть, что амплитуда сигнала в ряду $\mathrm{ZnS}^{\mathrm{HP}}-\mathrm{ZnS}^{\mathrm{CVD}}-\mathrm{ZnS} \mathrm{CVD}+\mathrm{HIP}$ растет с увеличением размера зерна (см. таблицу). В пластичных кристаллах первичная деформация при разрушении начинается с движения заряженных дислокаций [13-15]. Межзеренные границы являются для них барьером [16,17], поэтому изменение размера кристаллитов в различных керамических материалах одного и того же химического состава отражается на движении дислокаций. Самая высокая амплитуда ЭМЭ наблюдалась в керамике $\mathrm{ZnS} C \mathrm{DD}+\mathrm{HIP}$, имеющей весьма слабовыраженные границы между зернами [12].

В образце $\mathrm{ZnS}^{\mathrm{HP}}$ с наименьшим средним размером зерен интенсивность пиков была наименьшей, и основной максимум появлялся с наибольшей временно́й задержкой (рис. 1). По-видимому, это связано с тем, что в мелкозернистом материале пластическая деформация незначительна из-за проскальзывания кристаллитов, и после достижения предельной деформации в межзеренном пространстве зарождаются и растут трещины, на противоположных границах которых возникает постепенно релаксирующий излучающий диполь [8]. Чтобы проверить это предположение, временнб́е развертки ЭМЭ из образца $\mathrm{ZnSe} \mathrm{PVD}^{\mathrm{PVIP}}$ были сопоставлены с параллельными временны́ми сериями сигналов МЛ и АЭ (рис. 2). В сериях ЭМЭ и АЭ имелось по одному пику, тогда как сигнал МЛ представлял собой дублет. При этом положе-

Письма в ЖТФ, 2018, том 44, вып. 15 


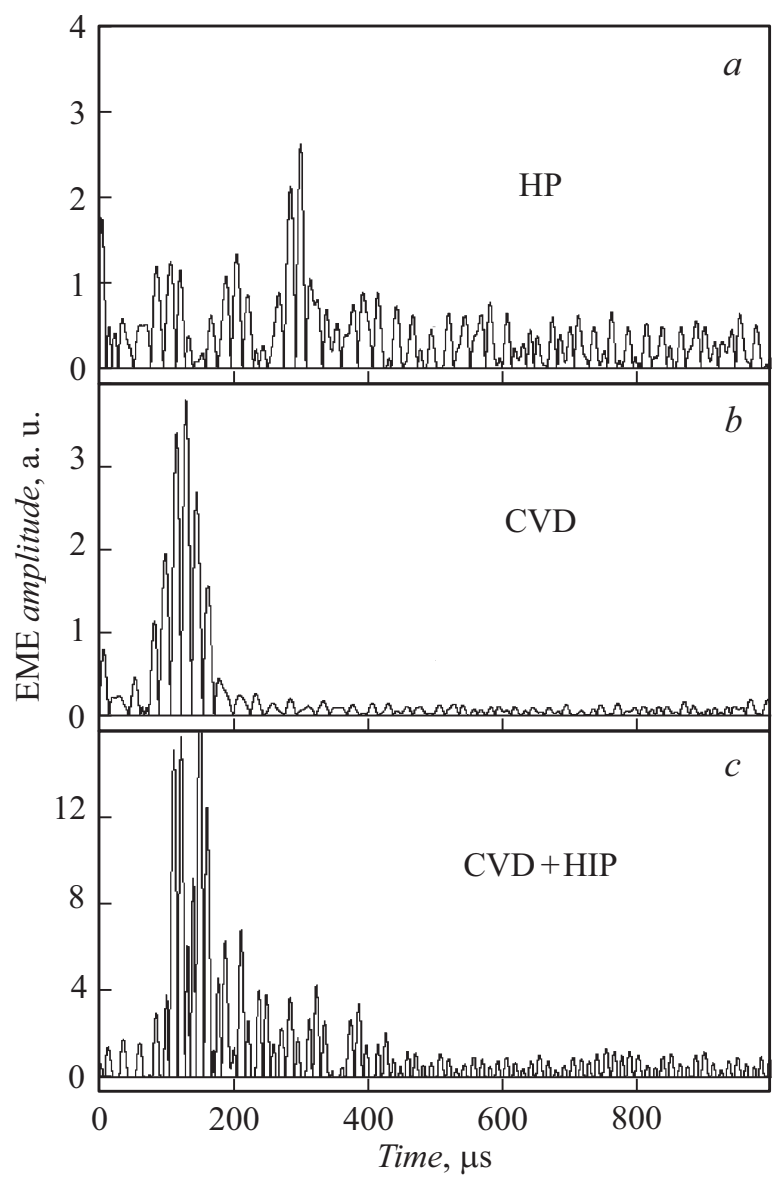

Рис. 1. Индуцированная ударом ЭМЭ из керамик $\mathrm{ZnS}$, полученных методами $\mathrm{HP}(a), \mathrm{CVD}(b)$ и $\mathrm{CVD}+\mathrm{HIP}(c)$.

ние пика ЭМЭ приблизительно совпало с положением первого по времени пика МЛ, а положение пика АЭ - с положением второго пика МЛ. Подобный результат также был получен на образцах керамики $\mathrm{ZnS} \mathrm{CVD}^{\mathrm{H}+\mathrm{HP}}$, имеющих наиболее совершенную кристаллическую структуру.

Письма в ЖТФ, 2018, том 44, вып. 15 


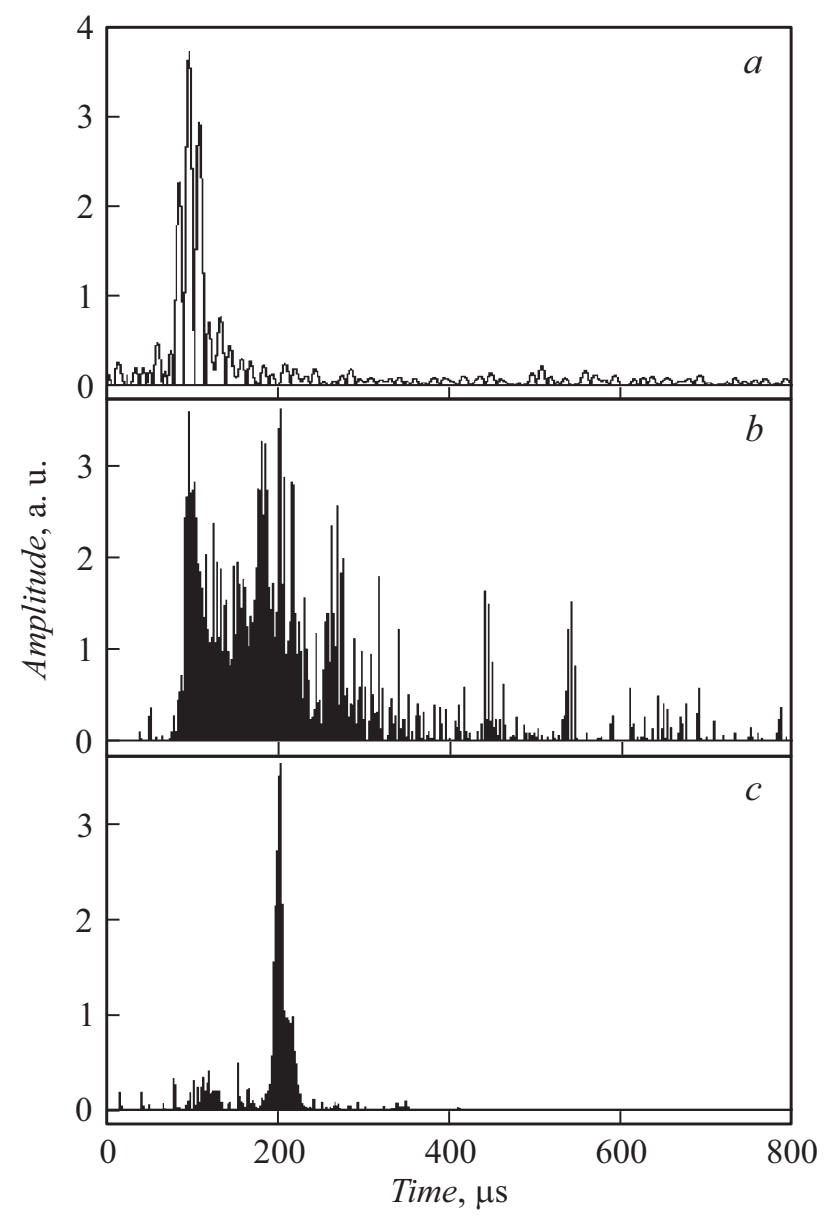

Рис. 2. Индуцированные ударом ЭМЭ $(a)$, МЛ $(b)$ и АЭ $(c)$ из керамики $\mathrm{ZnSe} \mathrm{PVD}^{\mathrm{PHIP}}$.

Эффект МЛ при пластическом деформировании $\mathrm{A}_{2} \mathrm{~B}_{6}$ также обусловлен движением заряженных дислокаций, создающих сильное электрическое поле, в котором происходит туннелирование электронов из ловушек в зону проводимости; люминесценция возникает при реком-

Письма в ЖТФ, 2018, том 44, вып. 15 
бинации электрон-дырка $[15,18]$. Этот процесс совпадает по времени с сигналом ЭМЭ и первым пиком МЛ на рис. 2. Второй пик МЛ, приблизительно совпадающий по времени с максимальной амплитудой АЭ, вызван массовым разрывом межатомных связей при зарождении и росте трещин [9].

Обобщая полученные результаты, приходим к заключению, что при ударном разрушении керамик $\mathrm{A}_{2} \mathrm{~B}_{6}$ имеет место значительная пластическая деформация материала с генерацией ЭМЭ. При достижении предельной деформации возникают трещины, регистрируемые методами МЛ и АЭ, но ЭМЭ из них наблюдалась только в мелкозернистом материале, имеющем благоприятные условия для зарождения микротрещин в межкристаллитных прослойках с множественными разрывами межатомных связей.

\section{Список литературы}

[1] Головин Ю.И., Шибков А.А. // ФТТ. 1986. Т. 28. В. 11. С. 3492-3500.

[2] Альшич В.И., Даринская Е.В., Казакова О.Л. // ФТТ. 1987. Т. 29. В. 2. C. $1821-1825$.

[3] Головин Ю.И., Шибков А.А. // Кристаллография. 1987. Т. 32. В 2. С. $413-$ 416.

[4] Chishko K.A.. Charkina O.V. // Mater. Sci. Eng. A. 1997. V. 234-236. P. 361-364.

[5] Hadjicontis V., Mavromatou C., Ninos D. // NHESS. 2004. V. 4. N 5/6. P. 633639.

[6] Hadjicontis V., Mavromatou C., Antsygina T.N., Chishko K.A. // Phys. Rev. B. 2007. V. 76. N 2. P. 024106.

[7] Ogawa T., Oike K., Miura T. // J. Geophys. Res. 1985. V. 90. N D4. P. 62456249.

[8] Eftaxias K.A., Panin V.E., Deryugin Ye.Ye. // Tectonophysics. 2007. V. 431. N 1-4. P. 273-300.

[9] Щербаков И.П., Дунаев А.А., Кадомиев А.Г., Чмель А.Е. // ФТТ. 2016. Т. 58. B. 10. C. $1969-1972$.

[10] Jilbert G.H., Field J.E. // Wear. 2000. V. 243. N 1-2. P. 6-17.

[11] Савельева Н.В., Баяндин Ю.В., Савиных А.С., Гаркушин Г.В., Ляпунова Е.А., Разоренов С.В., Наймарк О.Б. // Письма в ЖТФ. 2015. Т. 41. В. 12. C. 32-39.

[12] Щуров А.Ф., Гаврищук Е.М., Иконников В.Б., Яшина Э.В., Сысоев А.Н., Шеваренков Д.Н. // Неорган. материалы. 2004. Т. 40. В. 4. С. 400- 403.

[13] Бредихин С.И., Шмурак С.3. // ЖЭТФ. 1977. Т. 73. В. 4. С. 1460-1469.

Письма в ЖТФ, 2018, том 44, вып. 15 
[14] Бредихин С.И., Шмурак С.3. // ЖЭТФ. 1979. Т. 76. В. 3. С. 1028-1037.

[15] Tiwari R., Dubey M.V., Ramrakhiani M., Chandra B.P. // Luminescence. 2015. V. 30. N 6. P. 883-890.

[16] Pelleg J. // Mechanical properties of materials. Dordrecht, Netherlands: Springer Science + Business Media, 2013. Ch. 3. P. 188.

[17] Kondo S., Mitsuma T., Shibata N., Ikuhara Y. // Sci. Adv. 2016. V. 2. N 11. P. e1501926.

[18] Thaker S., Shukla V.K., Baghel R.N. // J. Pure Appl. Ind. Phys. 2012. V. 2. N 3A. P. 390-397. 